\title{
TENGO MIEDO TORERO: LUGARES E ANTILUGARES DE REPRESENTAÇÃO DA LOCA LATINO-AMERICANA
}

Eder Porto de Santana (UFBA) Júlia Morena Costa (UFBA)

Resumo: Através da análise de Tengo Miedo Torero, único romance do escritor chileno Pedro Lemebel, objetivamos entender como os corpos políticos dicotomicamente representados na narrativa se articulam como uma construção performática do autor, inserido no seu projeto de militante da memória nacional chilena. Mais especificamente, buscamos discutir a representação destes corpos e seus espaços privados e públicos, assinalando algumas inadequações e insuficiências políticas promovidas por modelos de gênero culturalmente construídos e ainda cristalizados.

Palavras-chave: Homorrepresentatividade, Pedro Lemebel, Corpo político.

Resumen: A través del análisis de Tengo Miedo Torero, única novela del escritor chileno Pedro Lemebel, objetivamos entender cómo los cuerpos políticos dicotómicamente representados en la narrativa se articulan como una construcción performática del autor, insertado en su proyecto de militante de la memoria nacional chilena. Más específicamente, buscamos discutir la representación de estos cuerpos y sus espacios privados y públicos, señalando algunas inadecuaciones e insuficiencias políticas promovidas por modelos de género culturalmente construidos y todavía cristalizados

Palabras-clave: Homorrepresentatividad, Pedro Lemebel, Cuerpo político.

Pedro Lemebel, artista plástico, performer e escritor chileno, vem se destacando no cenário cultural e político do Chile desde a década de 1980, quando figurava no coletivo de arte Las Yeguas del Apocalipisis, com o qual protagonizou diversas performances artísticas, 
mesclando fatos biográficos e ficção, parodiando ícones hollywoodianos e a moral do regime sociopolítico da época (ROBINO, 1991, p. 42) - uma das mais violentas ditaduras militares da América Latina, liderada por Augusto Pinochet. É neste período também que o autor se voltou à escrita em oficinas literárias, onde foi tecendo suas redes intelectuais, políticas e afetivas, que o vincularam ao mundo acadêmico das Letras e, paralelamente, à contracultura da época e ao movimento de resistência à ditadura pinochetista (ROBINO, 1991, p. 43). A escrita de Lemebel não se distingue da sua militância que, além de ser o meio como ele expressa a sua "inadequação" sociopolítica - enquanto homossexual, ameríndio e de origem pobre -, é também a forma como ele elabora suas diversas identidades coletivas e marginalizadas, que ainda contam com poucas escritas que simbolizem os seus lugares de existência e que thes garantam uma voz política legitimada no campo das letras.

Como explica Tocornal Orostegui (2007), as crônicas de Lemebel cuidarão das duas fases da Ditadura chilena. A primeira fase é chamada terrorista, iniciada com o golpe de 1973 e identificada como

$$
\begin{aligned}
& \text { um grande ato ordenador } \\
& \text { fraudulentamente associado às } \\
& \text { seguranças básicas do indivíduo e suas } \\
& \text { concepções de pureza e poluição, de }
\end{aligned}
$$


classificação e identidade, de pecado e perdão, de culpa e vergonha, de domínio e produção, do permitido e do tabu ${ }^{1}$. (RICHARD, 2007, p. 30-31)

Pedro Lemebel representa este período pelas crônicas que denunciam a sistemática de perseguições e violências do regime, justificadas pela noção de ordem e por uma cidadania padronizada na lógica dos modelos econômicos.

A segunda fase é a constitucional, que se inicia em 1980, se retarda até o plebiscito de 1988, e marcou a transição democrática. É neste período, e até mais além dele, que se atritam as forças políticas que advogam em favor da conservação dos valores ditatoriais e as que questionam e denunciam os custos sociais de um regime repressor, que gerou tantas vítimas:
A posição estético-política do escritor Pedro Lemebel encarna este compromisso intelectual tanto em sua intolerância civil às chamadas "leis que esquecem", como a luta política da diferença sexual. Tanto a politização da diferença como a politização da memória formam parte da sua agenda de escrita². (BLANCO, F. 2004 Apud TOCORNAL OROSTEGUI, 2007, p. 5)

\footnotetext{
1 "un gran acto ordenador fraudulentamente asociado a las seguridades básicas del individuo y sus concepciones de pureza y polución, de clasificación e identidad, de pecado y perdón, de culpa y vergüenza, de dominio y producción, de lo permitido y lo tabú." (Tradução nossa)

2 "La posición estético política del escritor Pedro Lemebel encarna este compromiso intelectual tanto en su adscripción a la intolerancia civil a las llamadas 'leyes de olvido' como la lucha por la política de la diferencia sexual. Tanto la politización de la diferencia como la politización de la memoria forman parte de su agenda de escritura." (Tradução nossa)
} 
Tengo Miedo Torero (2002), único romance de Pedro Lemebel em meio a diversas publicações de crônicas, se localiza narrativamente em 1986, ano conhecido como o do atentado ao ditador chileno, ainda durante o regime militar. A narrativa constrói-se em torno da Loca del Frente, personagem de tipologia recorrente na obra lemebeliana, apelidada na vizinhança do bairro popular não apenas para referenciar o seu endereço na rua, mas para localizar o seu universo à parte, o mundo introspectivo onde a $10 \mathrm{ca}^{3}$ se dramatiza embalada pela poética de boleros, tangos e rancheras antigos:

Todo o bairro sabia que o novo vizinho era assim, a donzela da quadra muito encantada com essa construção arruinada. Uma borboletona de sobrancelhas franzidas que chegou perguntando se alugavam esse escombro chacoalhado da esquina [...] Só Ihe falta o príncipe, cochichavam as velhas da calçada da frente, seguindo seus movimentos de beija-flor na janela. Mas é simpático, diziam, escutando suas líricas fora de moda, seguindo com a cabeça o compasso desses temas de ontem que acordavam o quarteirão inteiro [...] Como se quisesse compartilhar com o mundo inteiro essa música brega que tirava o sono dos vizinhos com esse "Y...y

3 Optamos por não traduzir o termo Loca por ser o nome do personagem, mas que, em tradução livre poderia ser relacionado ao vocábulo "bicha" no Brasil. 
tu maano to-o-o-o-mará la mía-a-a-a." (LEMEBEL, 2002, p. 8-9)

A casa da loca, um importante local de construção da personagem e do cenário para sua relação com a política e com Carlos, é um elemento alegórico do romance que marca uma preferência de Lemebel por estéticas kitsch e o camp que, segundo Neyret (2006), são consideradas despolitizadas e associadas ao mau gosto artístico. Tratamse de terminologias que no campo teórico atribuem ao fenômeno brega a propriedade de metaforizar o sentimento de marginalidade próprio da cultura latino-americana em relação à cultura ocidental (NEYRET, 2006, p. 3) e que na sua literatura ganha destaque:

Aquela casa primaveral de 1986 era seu bálsamo. Talvez a única coisa amada, o único espaço da Loca del Frente. Por isso o afã de decorar suas paredes como bolo de casamento. Emoldurando as quinas com pássaros, leques, trepadeiras floridas e esses xales filipinos pendurados de um piano invisível. Esses franjados, malhas e babados de tule que forravam

\footnotetext{
4 "Todo el barrio sabía que el nuevo vecino era así, una novia de la cuadra demasiado encantada con esa ruinosa construcción, un maripozuelo de cejas fruncidas que llegó preguntando si se arrendaba ese escombro terremoteado de la esquina [...] Sólo le faltaba el novio, cuchicheaban las viejas en la vereda del frente, siguiendo sus movimientos de picaflor en la ventana. Pero es simpático, decían, escuchando sus líricas pasadas de moda, siguiendo con la cabeza el compás de esos temas de ayer que despertaban toda la cuadra [...] Como si quisiera compartir con el mundo entero la letra cursi que depegaba del sueño a los vecinos con ese "Y... y tu mano to-o-o-mará la mía-a-a-a": (Tradução nossa)
} 
os caixotes usados como mobiliário ${ }^{5}$. (LEMEBEL, 2002, p. 10)

García-López também comenta essa politização das estéticas kitsch e camp:

mais que a miséria e suas sequelas, é uma outra marginalidade que interessa para Pedro Lemebel: aquela que resulta da dissidência política [...] Aquela que dá um sentido a essas formas de resistência. As divergências dessas estéticas as levam a circunstâncias de exceção no interior da sociedade, para que elas questionem os valores dominantes. Assim, os homossexuais, os jovens, as mulheres, entre outros, as prostitutas, os vagabundos se tornam visíveis sob a escrita do cronista-queer, torcem o nariz da economia neoliberal baseada na hiperprodução e no hiperconsumo ${ }^{6}$. (LÓPEZ-GACÍA, 2008, p. 82)

O contraponto estético da casa da Loca del Frente é a casa fascista, nos Bairros Altos de Santiago, aonde certa vez ela se dirige para entregar um trabalho de toalha de mesa

5 “Aquella casa primaveral del 86 era su tibieza. Tal vez lo único amado, el único espacio pobre que tuvo la Loca del Frente. Por eso ese afán de decorar sus muros como torta nupcial. Embetunando las cornisas con pájaros, abanicos, enredaderas de nomeolvides, y esas mantillas de Manila que colgaban del piano invisible. Esos flecos, encajes y joropos de tul que envolvían los cajones usados como mobiliario". (Tradução nossa)

6 “[...] plus que la misère et ses séquelles, c’est une autre marginalité qui constitue le centre d'intérêt primordial pour Pedro Lemebel : celle qui résulte de la dissidence politique [...]Ce qui donne un sens à ces formes derésistance, c'est qu'elles s'attaquent à des tabous. Leurs divergences les conduisent à des situations d'exception à l'intérieur de la société, parce qu'elles mettent en cause les principes directeurs en vigueur. Ainsi, les homosexuels, les jeunes, les femmes, entre autres, les prostitués, les vagabonds deviennent visibles sous la plume du " chroniqueer » et font un pied de nez à l'économie néolibérale de l'hyper production et de l'ultra consommation". (Tradução nossa) 
bordada - com passarinhos e querubins -, encomendada pela mulher de um dos generais de Pinochet. A Loca se depara com uma casa austera e com uma sala de jantar sombria com cortinas pesadas e louças finas, o que lhe faz aflorar imagens horripilantes e caricaturais dos militares sentados à mesa, associando o ato de comer com a violência gritante da época:

a dupla fileira de acolchoadas cadeiras forradas de seda cor de musgo, parecia uma ceia morta de comensais fantasmas. Ai, que tétrico! Lembra a mesa do Drácula [...] Primeiro os viu sérios e cerimoniosos antes do jantar, escutando os discursos [...] aplaudindo-se uns aos outros com vivas à pátria, vivas a guerra, vivas pelo onze de setembro porque tinham matado muitos comunistas [...] Ao longe trombeteava o hino marcial as galas de sua música que, altaneiro, se ouvia no compasso das gargalhadas dos generais famintos, mordendo a carne suculenta, mastigando com fúria as costelas gordurosas, sangrentas, que gotejavam de seus dentes e tingiam seus bigodes bem aparados. Estavam ébrios, eufóricos, não só pelo álcool, mas sim pelo orgulho [...] que vomitavam em seus palavrões de ódio. Em sua ordinária flatulência de afrouxarem o cinto para comerem as sobras. Para se enfastiarem deles mesmos no roer os ossos descarnados 
e vísceras frescas, maquiando seus lábios como palhaços macabros ${ }^{7}$. (LEMEBEL, 2002, p. 64-66)

Nestes ambientes privados, o público e o íntimo se confundem, garantindo o adentramento do campo político nestes espaços, que desta forma são também sociais.

Percebemos que a suposta dissidência política da Loca del Frente é um alheamento proposital. Ela conhece a situação política que vive, a cidade onde mora, sabe dos atos de violência e ouve os noticiários através do rádio - o mesmo rádio com o qual ela escuta suas músicas melancólicas, que são insistentemente interrompidas pelas notícias que "invadem" o seu espaço mais íntimo: a sua casa. Contudo, a deliberada politização da sua esfera privada só começa quando ela se deixa seduzir por Carlos, um jovem universitário membro da Frente Revolucionária Manuel Rodríguez, que planeja um atentado contra o ditador junto com seus companheiros. A Loca del Frente acaba abrigando Carlos, deixando que ele "penetre" a sua casa - metáfora usada pelo narrador, com forte homoerotismo -

7 "[...] la doble hilera de mullidos sillones tapizados de felpa color musgo, semejaban una cena muerta de comensales fantasmas !Ay qué tétrico! Parece la mesa del Drácula [...] Primero los vio graves y ceremoniosos antes de la cena escuchando los discursos [...] palmoteándose las espaldas con los salud por la patria, los salud por la guerra, los salud por el once de septiembre porque habían matado a tanto marxista [...] Muy de lejos trompeteaba el himno marcial las galas de su música que, altanero, se oía acompasado por las carcajadas de los generales babeantes mordiendo la carne jugosa, mascando fieros el costillar graso, sanguinolento, que goteaba sus dientes y entintaba sus bigotes bien recortados. Estaban ebrios eufóricos, no sólo de alcohol, más bien de orgullo [...] que vomitaban en sus palabrotas de odio. En su ordinaria flatulencia de soltarse el cinturón para engullir las sobras. Para hartarse de ellos mismos en el chupeteo de huesos descarnados y vísceras frescas, maquillando sus labios como payasos macabros". (Tradução nossa) 
com reuniões sigilosas e um material belicoso que ela mascara, fingindo desconhecer os seus planos de atentado e que ela rapidamente trata de incorporar na estética do restante do seu lar, mesclando a guerrilha e o adorno:

No umbral, Carlos e dois amigos carregavam um agressivo tubo de metal, que sem pedir permissão, introduziram adentro [...] Como ficou? Ela o recebeu mostrando-Ihe 0 estranho cilindro, enquanto acariciava com sua mãolagartixa os contornos do aço que ela revestiu com malhas de tule e laços de fita. Ficou ótimo, tratando de não olhar o assombro divertido dos olhos pardos de Carlos. Na verdade, nem dá para saber o que é, sussurrou Carlos dando uns passos emocionados, aproximandose dela, tomando-a por suas largas ancas de égua-bambi, atraindo-a a seu peito em abraço agradecido, deixando-a toda se tremendo, sem respirar. Como uma menina arrematada de rubor, como um caracol velho enroscado em seus braços, a centímetros do seu coração que fazia tic-tac tic-tac, como um explosivo enfiado na sua estética de brócolis maricas ${ }^{8}$. (LEMEBEL, 2002, p. 21-22)

8 "En el umbral, Carlos y dos amigos cargaban un agresivo tubo de metal, que sin preguntarle, introdujeron al interior [...] ¿Cómo se ve? Lo recibió mostrándole el raro ikebana, mientras acariciaba con su mano lagartija los contornos del acero revestido de blondas entuladas y moñas de cinta. Se ve precioso, tratando de no mirar el asombro divertido de sus ojos pardos. En verdad, no se nota lo que es, musitó Carlos dando unos pasos emocionados, acercándose, tomándola por sus gruesas ancas de yegua coliflor, atrayéndola a su pecho en un abrazo agradecido, dejándola toda temblorosa, sin respirar. Como una chiquilla enguindada de rubor, como una caracola antigua enroscada en sus brazos, a centímetros de su corazón haciendo tic-tac tic-tac, como un explosivo de pasión enguantado, por su estética de brócoli mariflor". (Tradução nossa) 
Paralelamente e em associação à construção do espaço da casa, destacamos a configuração do corpo da Loca, que metaforicamente fala e se encena através das marcas da sua marginalidade. Contudo, apesar do símbolo eminentemente político que possui este corpo, lhe é negado este lugar de pleito e luta política. Estabelece-se uma dicotomia entre o corpo da loca, associado à frivolidade e ao divertimento, e o estereótipo do varonil herói guerrilheiro de esquerda, afinal "Carlos era homem muito sério, e ela não ia deixá-lo passar vergonha com bichices de circo nem borlas de veado cancã"9 (LEMEBEL, 2002, p. 24). É então que a narrativa deixa entrever as marcas da memória melancólica da Loca, do seu corpo homossexual que deseja e não pode amar, dentro do ideário cultural do amor heterossexual, nas suas condições e que recorre à via marginal do universo do sexo de rua:

Retalhos de uma errância prostibular de cortiços sem nome, por ruas sujas que arrastam seu devaneado passeio tropical. Seu ritmo chocalheiro no vaivém da noite, a assédio oportuno de algum parceiro bêbado no seu baile, sustento do seu destino por algumas horas, por algumas moedas, por estar compartilhando esse frio andino com qualquer nádega quente. A todo esfregue vagabundo que a aparte da vida, lixando

9 "Carlos era hombre y muy serio, y ella no lo iba a avergonzar con mariconerías de farándula ni pompones de loca can-cán". (Tradução nossa) 
sua má sorte com o sexo. E depois uma cueca crispada, uma meia esquecida, uma garrafa vazia sem mensagem, sem rumo, nem ilha, nem mapa que ilumine seu coração andorinho10. (LEMEBEL, 2002, p. 15-16)

Neste romance, podemos perceber um forte conteúdo originário das artes visuais e o apelo frequente às formas estético funcionais do corpo. No enredo, La Loca del Frente, um homossexual pobre de meia idade, desenvolve uma relação sentimental com Carlos, um jovem guerrilheiro comunista que planeja um atentado contra o ditador Augusto Pinochet. Entender como estes corpos, dicotomicamente ali representados, se articulam dentro da narrativa, carece, antes de tudo, da compreensão da figura da loca latinoamericana como uma construção performática desse escritor, dentro do seu projeto de militante da memória nacional chilena. Mais precisamente, procuraremos discutir a representação desses corpos e seus espaços privados e públicos, demonstrando algumas inadequações e insuficiências políticas promovidas por modelos de gênero culturalmente construídos e ainda cristalizados.

10 "Retazos de una errancia prostibular por callejones sin nombre, por calles sucias arrastrando su entumida vereda tropical. Su son maraco al vaivén de la noche, el vergazo oportuno de algum ebrio pareja de su baile, sustento de su destino por algunas horas, por algunas monedas, por compartir ese frío huacho a toda cacha caliente. A todo refregón vagabundo que se desquita la vida lijando con el sexo la mala suerte. Y después un calzoncillo tieso, un calcetín olvidado, una botella vacía sin mensaje, sin rumbo, ni isla, ni tesoro, ni mapa donde enrielar su corazón golondrino". (Tradução Nossa) 
Entendemos a loca como o modelo queer local, afeminado, passivo e estigmatizado, que se diferencia do modelo gay nova-iorquino - este último não teria um caráter contestador dos padrões sociais heteronormativos - e que não se adequa à realidade da América Latina, enquanto periferia econômica do capitalismo neoliberal fortalecido pelas ditaduras militares, tal como a do Chile em 1973 (PALAVERSICH, 2002, p. 103).

A teoria queer se refere a este corpo da loca como o "estranho que incomoda, perturba e fascina" e, ainda, como "um jeito de pensar e de ser que desafia as normas regulatórias da sociedade, que assume o desconforto da ambiguidade, dos 'entre lugares', do indecidível" (LOURO, 2004 , p. 7-8). A ambiguidade decorre do fato de esse corpo transitar na fronteira das definições ou decisões que tentam desencadear um processo de fazê-lo masculino ou feminino (BUTLER, 1993 Apud LOURO, 2004, p. 15). O ato de nomear o corpo acontece no interior da lógica que supõe o sexo como um dado anterior à cultura e "Ihe atribui um caráter imutável, a-histórico e binário" (BUTLER, 1993 Apud LOURO, 2004 , p. 15). Para qualificar-se como sujeito legítimo, como "corpo que importa", o sujeito se verá obrigado a obedecer às normas que regulam a sua cultura (BUTLER, 1999 Apud LOURO, 2004, p. 16). 
No tocante à análise aqui apresentada, percebemos essa íntima relação entre sua escrita e o sujeito autobiográfico, uma vez que o autor Pedro Lemebel mesclará experiências de vida com identidades por ele incorporadas através do texto: “o corpo torna-se então o ponto de mediação entre uma série de relações binárias de oposição, tais como interior e exterior, sujeito e mundo, público e privado, subjetividade e objetividade. O corpo é o lugar onde essas antinominias ocorrem" (BERSTEIN, 2004, p. 256).

A Loca, marginalizada pelos padrões heteronormativos, é também excluída pelas forças políticas que disputavam o cenário neste momento. Tanto a macroesquerda quanto as forças direitistas negarão o pertencimento deste sujeito que não acata a dicotomia e padronização do gênero. Tentarão, em maior ou menor medida, sujeitar este corpo às suas normas ou ainda impedi-lo de pertencer aos ambientes oficiais ou de centro. Esta sujeição do corpo da Loca tem inícios desde sua infância e começa dentro do espaço privado da sua casa:

Ele mandava eu me portar como homem, que por isso me batia, que não o queimasse com seus amigos do sindicato, Ihes dizendo que eu tinha nascido errado. Logo com ele, tão macho, tão viciado em mulheres, tão metido com putas, tão bêbado, naquela vez me manuseando. 
Tão ardente seu corpo elefante em cima de mim, me cutucando, me sufocando na penumbra do quarto, no desesperado debater-se como um frango empalado, como um criado depenado, sem corpo nem coragem para resistir o impacto do seu nervo duro me eriçando. ${ }^{11}$ (LEMEBEL, 2002, p. 15-16)

É uma violência praticada por seu próprio pai, apresentado por uma identificação política com a esquerda sindicalista, mas incapaz de aceitar ou entender as manifestações de seu filho. Violentamente, tentará adequar este corpo a um padrão, através da violação desta criança ou da ameaça de incorporação deste corpo nas forças armadas, conhecida instância de legitimação de um comportamento heteronormativo e de padronização, controle e adequação dos corpos de seus integrantes. Esta violência, que começa em casa e que está sujeitada por uma vergonha pública é já uma primeira mostra de inter-relação entre os espaços público e privado no exercício da violência contra um corpo que "desvia" da norma.

Mas não só a esquerda negará este corpo no romance. Também a direita se mostrará intolerante a este sujeito

11 “Él decía que me hiciera hombre, que por eso me pegaba, ni pelarse con sus amigos del sindicato grintándole que yo había salido fallado. A él tan macho, tan canchero con las mujeres, tan encachao con las putas, tan borracho esa vez manoseando. Tan ardiente su cuerpo elefante encima de mí punteando, ahogándome en la penumbra de esa pieza, en el desesperado aletear como pollo empalado, como pinchón sin plumas, sin cuerpo ni valor para resistir el impacto de su nervio duro erizándome". (Tradução Nossa) 
desviante. O ditador, na sua casa de campo, não suporta ver um dos seus oficiais não seguindo o comportamento esperado pela padronização militar. Este corpo que não se enquadra na heteronormatividade exigida pelo personagem Pinochet é expulso arbitrariamente por este:

De onde foi que saiu esse passarinho afeminado, perguntou ao secretário apontando para o cadete que se dirigia até o bosque acompanhado da escolta. É sobrinho do Coronel Abarzúa, meu General. Como é que permitem que essa gente torta entre na Escola Militar? Ele foi recomendado pelo Coronel Abarzúa [...] Que sã consciência foi essa que deixou um veado usar uniforme de cadete? Você não sabe que esses desviados são iguais aos comunistas, uma verdadeira praga, onde tem um... ligeirinho convence o outro e assim, em pouco tempo, o Exército vai parecer casa de putas. ${ }^{12}$ (LEMEBEL, 2002, p. 155-156)

Muito embora essas dicotomias preexistam a Tengo Miedo Torero (2002), no romance passam por uma série de desmitificações. Primeiramente, a dicotomia loca e guerrilheiro de esquerda é desfeita pela aproximação afetiva

12 “¿Y de dónde salió este pájaro afeminado?, preguntó al secretario apuntado al cadete que se alejaba hasta el bosque acompañado por el escolta. Es sobrino del coronel Abarzúa, mi General. ¿Cómo se les ocurre dejar estos raros entrar en la Escuela Militar? Lo recomendó el coronel Abarzúa [...] En qué cabeza les cabe permitir que un maricón use uniforme de cadete? ¿No sabe usted que estos desviados son iguales que los comunistas, una verdadera plaga, donde hay uno... ligerito le convence a otro y así, en poco tiempo el Ejército va a parecer casa de putas". (Tradução Nossa) 
e até onírica entre Carlos e a Loca Del Frente:

Você me faz bem; quando estou com você eu fico alegre. Nem que eu fosse uma boneca engraçada. Não é isso, contigo eu me sinto otimista. E o quê mais? O que mais você quer? Que você me ame um pouquinho. Você sabe que eu gosto de você mais que um pouquinho. Não é a mesma coisa, entre amar e gostar há um mundo de diferença. Não é a mesma coisa. Contaría la arena del mar (com os olhos entreabertos). Por tí sería capaz de matar. Admiro a memória que você tem para decorar canções. Esta é antiga, mas é muito bonita, fala sobre tudo aquilo que alguém pode fazer quando se ama. Eu faria o mesmo, mas pelo Chile. E você acha que este país te agradeceria se você desse a vida? Você acha que eu dou uma de herói? Algo do tipo, talvez não como O'Higgins ou Prat, mas sim como Che Guevara. E você sabe quem foi Che Guevara? Um tesão de homem, uma maravilha de homem com aqueles olhos, com aquela barba, com aquele sorriso. E o quê mais? $E$ você acha pouco? E não te interessa conhecer qual era o seu sonho de mundo? O que pensava? Pelo que sacrificou a sua vida pela causa dos pobres? Seria tão romântico e valente como você. Você está enchendo minha bola, princesa, Carlos ficando sem graça, mas estou muito distante dessa figura [...] E você derramaria alguma lágrima por mim, princesa? Uma apenas, nada mais que 
uma, pequenina, pequenina, como uma pérola amarga que ficou sem $\operatorname{mar}^{13}$. (LEMEBEL, 2002, p. 143-144)

Lugares incólumes de masculinidade e "hombridade" também são desmentidos. De um lado, através de Carlos, guerrilheiro esquerdista, que confessa já ter tido uma experiência homoerótica com um amigo na adolescência e que o coito carnal só não ocorreu porque nenhum dos dois queria fazer o papel passivo. De outro, a fibra do homem militar é, por sua vez, destrinchada à medida que o ditador Augusto Pinochet é retratado na sua intimidade, como um velhinho de saúde vulnerável, controlado pela esposa e atormentado por pesadelos de perseguição. Durante o atentado da Frente Revolucionária, o general, de quem se espera sempre uma posição de resistência, demonstra o medo mais ridículo, fugindo encurralado:

Se jogue no chão, General, gritou-lhe o motorista desesperado, mas já tinha

13 Me haces tan bien; cuando estoy contigo me pongo contento. Ni que yo fuera una muñeca para la risa. No es eso, contigo me siento optimista. ¿Y qué más? ¿Qué más quieres? Que me ames un poquito. Tú sabes que te quiero más que un poquito. No es lo mismo, entre amar y querer hay un mundo de diferencia. No es lo mismo. 'contaría la arena del mar' (con los ojos entornados). 'Por ti yo sería capaz de matar. Admiro la memoria que tienes para guardar canciones. Esta es antigua pero es muy bonita, dice todo lo que uno puede hacer por alguien que se ama. Yo haría lo mismo, pero por Chile. ¿Y tú crees que este país te agradecería que le des la vida? ¿Tú piensas que me creo héroe? Algo así, tal vez no como O’Higgins o Prat, pero sí como el Che Guevara. ¿Y tú conoces quién fue el Che Guevara? Un bombonazo de hombre, una maravilla de hombre con esos ojos, con esa barba, con esa sonrisa. ¿Y qué más? ¿Y te parece poco? ¿Y no te interesa saber cuál era su sueño de mundo? ¿Qué pensaba? ¿Por qué le entregó su vida a la causa de los pobres? Sería tan romántico y valiente como tú. Me halaga usted, princesa, se sonrojó Carlos, pero estoy muy lejos de esta figura. [...] ¿Y usted derramaría alguna lágrima por mí, princesa? Una sola, nada más que una, pequeñita, pequeñita, como una perla amarga que se quedó sin mar." (Tradução Nossa) 
tempo que o Ditador já estava com o nariz encostado no chão, tremendo, gaguejando: Ma-mamãe-zi-zinha-lin-dada essa porra é real. E tão real que o pavor dos guardas não os deixavam reagir. $E$ pálidos se escondiam feito ratos no fragor do tiroteio ${ }^{14}$. (LEMEBEL, 2002, p. 172)

Para consumar essa série de desmitificações, apontamos como Pedro Lemebel promove a inserção política da Loca na efervescência dos protestos da Santiago de 1986. A Loca del Frente assume para si que "para a sorte dela, havia chegado Carlos a sua vida, mostrandoIhe a realidade cruel que rodeava os chilenos. Esse tirano infame que manda no país desde o Palácio La Moneda"15. Seu corpo então, como no poema de Néstor Perlonguer, se submerge "nos cheiros e sabores, nas sensações da cidade" e, inevitavelmente, "o corpo que erra conhece com/em seu deslocamento"16 (LEMEBEL, 2002, p. 12). Em meio aos protestos contra Pinochet, ela se detém para apanhar um cartaz com mensagem antifacista e acaba sentindo a represália da polícia:

14 "Tírese al suelo, mi General, le gritó el chofer desesperado, pero hacía rato que el Dictador tenía la nariz pegada al piso, temblando, tartamudeando: Ma-mama-cita-linda esta guevá es cierta. Y tan cierta que el pavor de los escoltas no los dejaba reaccionar. Y como pálidos se escondían como ratas en el fragor de la balacera". (Tradução nossa)

15 "Y por suerte para ella, había llegado Carlos a su vida mostrándole la realidad cruel que rodeaba a los chilenos. Ese tirano infame que mandonea el país desde la Moneda". (Tradução nossa)

16 "en los olores y los sabores, en las sensaciones de la ciudad/el cuerpo que erra conoce con/ en su desplazamiento". (Tradução nossa) 
Põe isso no chão, seu veado fodido, the gritou o polícia com fúria. E vai saindo daqui, vai fazer suas viadagens em outro canto, se não quiser que eu te leve preso. E a loca não esperou que ele repetisse a ordem, fazendo-se fumaça entre os transeuntes que lhe abriam caminho com susto [...] sentindo mais que dor, a humilhação de ser golpeado por esse cão de uniforme verde: sem motivo, sem razão nenhuma, estes desgraçados dão paulada, torturam e até matam com o consentimento do tirano. Malditos assassinos, pensou, mas já vão ver quando Carlos e seus amigos da Frente lhes fizerem voar o rabo com uma bomba $^{17}$. (LEMEBEL, 2002, p. 164)

Logo depois, a Loca del Frente se depara com um grupo de mulheres que reclamam os corpos desaparecidos de seus entes queridos e é através da identificação com o feminino que a personagem se agrega ao movimento, alçando sua "voz de falsete" e somando-se ao descontentamento.

Entretanto, a problemática da discussão de gênero não se satisfaz e não se resolve com a politização da Loca, pois a personagem continua no limbo das representatividades políticas que defendem a suas próprias demandas, de acordo com suas

17 “¡Bótalo, maricón culiao!, le gritó el paco mirándolo con furia. Y córrete de aquí, anda a mariconear a otro lado, si no querís que te lleve preso. Y la loca no esperó que le repitieran la orden, haciéndose humo entre los transeúntes que le abrían paso con susto [...] sintiendo más que dolor, la humillación de ser golpeado por ese perro de uniforme verde: Sin motivo, sin ninguna razón, estos desgraciados apalean, torturan y hasta matan con el consentimiento del tirano. Malditos asesinos, pensó, pero ya van a ver cuando Carlos y sus amigos del Frente les vuelen la raja de un bombazo". (Tradução nossa) 
peculiares questões identitárias. Trata-se de um ponto bastante sensível dentro da militância do escritor Pedro Lemebel e ainda mal resolvido mesmo no Chile atual redemocratizado, mas com tantos resquícios de valores políticos e sociais do regime de Pinochet. $\mathrm{O}$ autor Pedro Lemebel reiteradamente também se apresenta como este corpo não inscrito e adaptado às dicotomias restritivas e autoritárias de gênero ao se apresentar publicamente travestido, como no lançamento da obra aqui analisada ou ao posar para as capas de seus outros livros, o que causa certo estranhamento no machismo latente latinoamericano, seja ele de esquerda ou de direita. Em um dos seus textos clássicos, Manifiesto (Hablo por mi diferencia), de setembro de 1986, lido em um ato de esquerda em Santiago, Lemebel afirma: "minha hombridade/macheza não obtive do partido, porque me rejeitaram com risinhos várias vezes. Minha hombridade/macheza aprendi participando na dureza destes anos, e riram de minha voz afeminada [...] Minha hombridade/ macheza é me aceitar diferente"18 (LEMEBEL, 2008, p. 16). É então que a voz da Loca se funde na voz do próprio Pedro Lemebel e este corpo físico da performance se confunde com um discurso de uma coletividade que ainda precisa conseguir maior inserção dentro de um cenário político democrático.

18 "Mi hombría no la recibí del partido, porque me rechazaron con risitas muchas veces. Mi hombría la aprendí participando en la dura de esos años, y se rieron de mi voz amaricona [...] Mi hombría es aceptarme diferente". (Tradução nossa) 


\section{REFERÊNCIAS}

BERNSTEIN, Ana. "Performance solo e sujeito autobiográfico". In: SÜSSEKIND, F.; DIAS, T. (Org.). A historiografia literária e as técnicas de escrita: do manuscrito ao hipertexto. Rio de Janeiro: Edições Casa de Rui Barbosa: Vieira e Lent, 2004. p. 256-278.

LEMEBEL, Pedro. Tengo Miedo Torero. Santiago: Seix Barral. Buenos Aires: Seix Barral. 2002. 217 p.

LÓPEZ GARCÍA, Isabelle. Esthétique queer et politique dans 'Quiltra Lunera' de Perlas y Cicatrices de Pedro Lemebel. Lectures du genre: Lectures théoriques, approches de la ficction, n.5, p. 77-84, 2008. Disponível em:http://www.lecturesdugenre.fr/lectures_du_genre_5/Lopez.html. Acesso em: 13 de fevereiro de 2013.

LOURO, Guacira L.. Um Corpo Estranho - Ensaios sobre sexualidade e teoria queer. Belo Horizonte: Autêntica Editora, 2004, 92 p.

NEYRET, Juan Pablo. Entre acción y actuación: La politización del kitsch en El beso de la mujer araña de Manuel Puig y Tengo miedo torero de Pedro Lemebel. Espéculo: Revista de Estudios Literarios, Universidad Complutense de Madrid, n.34. 2006. Disponível em: http://www.ucm.es/ info/especulo/numero36/puiglebe.html. Acesso em: 13 de fevereiro de 2014.

PALAVERSICH, Diana. The Wounded Body of Proletarian Homosexuality in Pedro Lemebel's Loco afán. Tradução para o inglês de Paul Allatson. Latin American Perspectives: Gender, Sexuality, and Same-Sex Desire in Latin America, v.29, n.2, p. 99-118, Mar. 2002.

RICHARD, Nelly. Fracturas de la memoria: Arte y pensamiento crítico. Buenos Aires: Silgo XXI Editores Argentina, 2007.

ROBINO Z., Carolina. Las últimas locas del fin del mundo: las Yeguas del Apocalipsis. Hoy. Santiago de Chile: Araucaria, 1977-1998, v.21, n.736, p. 42-45, ago. 1991. Disponível em: http://www.memoriachilena.cl/temas/ documento_detalle.asp?id=MC0044769. Acesso em: 14 de fevereiro de 2014. 
TOCORNAL OROSTEGUI, Catalina. Una mirada a "la loca" de Pedro Lemebel: de figura privilegiada a figura paradigmática. 2007. Dissertação (Mestrado em Literatura/Literatura Chilena e Hispanoamericana) Faculdade de Filosofia e Humanidades, Universidade do Chile, Santiago. Disponível em: http://www.tesis.uchile.cl/tesis/uchile/2007/tocornal_c/ html/index-frames.html. Acesso em: 21 abril 2014.

Eder Porto de Santana é professor substituto de literatura de língua espanhola no Instituto de Letras da Universidade Federal da Bahia. Graduado em Língua Estrangeira (espanhol) pela UFBA e em Direito pela Universidade Católica do Salvador. Atualmente cursa o mestrado em Literatura e Cultura na Universidade Federal da Bahia.

Júlia Morena Costa é professora do Instituto de Letras da Universidade Federal da Bahia. Graduada em Letras pela Universidade Federal de Minas Gerais e Mestre em Teoria da Literatura também pela UFMG. Atualmente está cursando o doutorado em Literatura e Cultura na Universidade Federal da Bahia. 